\title{
20-O-( $\beta$-D-glucopyranosyl)-20(S)-protopanaxadiol induces apoptosis via induction of endoplasmic reticulum stress in human colon cancer cells
}

\author{
RUI ZHANG ${ }^{1}$, YOUNG CHUNG ${ }^{2}$, HEE SUN KIM ${ }^{3}$, DONG HYUN KIM ${ }^{4}$, \\ HYE SUN KIM ${ }^{5}$, WEON YOUNG CHANG ${ }^{1}$ and JIN WON HYUN ${ }^{1}$
}

\author{
${ }^{1}$ School of Medicine and Applied Radiological Science Research Institute, Jeju National University, \\ Jeju 690-756, Republic of Korea; ${ }^{2}$ Pharmaceutical Chemistry, University of California, Davis, CA 95616, \\ USA; ${ }^{3}$ Department of Neuroscience, College of Medicine, Ewha Womans University, Seoul 110-783; \\ ${ }^{4}$ Department of Microbial Chemistry, College of Pharmacy, Kyung Hee University, Seoul 130-701; \\ ${ }^{5}$ Cancer Research Institute, Seoul National University College of Medicine, Seoul 110-799, Republic of Korea
}

Received July 4, 2012; Accepted September 14, 2012

DOI: $10.3892 /$ or.2013.2270

\begin{abstract}
Previously, we reported that 20-O-( $\beta$-D-glucopyranosyl)-20(S)-protopanaxadiol (Compound $\mathrm{K}$, a metabolite of ginseng saponin) induces mitochondria-dependent and caspase-dependent apoptosis in HT-29 human colon cancer cells via the generation of reactive oxygen species. The aim of the present study was to elucidate the mechanism underlying apoptosis induced by Compound $\mathrm{K}$ with respect to endoplasmic reticulum (ER) stress in HT-29 cells. In the present study, Compound $\mathrm{K}$ induced apoptotic cell death as confirmed by DNA fragmentation and apoptotic sub- $\mathrm{G}_{1}$ cell population. Compound $\mathrm{K}$ also induced ER stress as indicated by staining with ER tracker, cytosolic and mitochondrial $\mathrm{Ca}^{2+}$ overloading, phosphorylation of protein-kinase-like endoplasmic reticulum kinase (PERK), phosphorylation of eukaryotic initiation factor-2 $\alpha$ (eIF-2 $\alpha$ ), phosphorylation of IRE-1, splicing of ER stress-specific X-box transcription factor-1 (XBP-1), cleavage of activating transcription factor-6 (ATF-6), upregulation of glucose-regulated protein-78 (GRP-78/BiP) and CCAAT/enhancer-binding protein-homologous protein (CHOP), and cleavage of caspase-12. Furthermore, downregulation of CHOP expression using siCHOP RNA attenuated Compound K-induced apoptosis. Taken together, these results support the important role of ER stress response in mediating Compound $\mathrm{K}$-induced apoptosis in human colon cancer cells.
\end{abstract}

Correspondence to: Professor Jin Won Hyun or Professor Weon Young Chang, School of Medicine, Jeju National University, 66 Jejudaehakno, Jeju 690-756, Republic of Korea

E-mail: jinwonh@jejunu.ac.kr

E-mail: orkorea@jejunu.ac.kr

Key words: Compound K, apoptosis, endoplasmic reticulum stress, CCAAT/enhancer-binding protein-homologous protein

\section{Introduction}

The endoplasmic reticulum (ER) is a secretory organelle, which plays a critical role in lipid synthesis and protein folding and modification before export to the Golgi body. Protein folding is impaired under unbalanced redox state, failure of protein synthesis, misfolding, transport or degradation and $\mathrm{Ca}^{2+}$ overloading, which can result in ER stress (1-3). ER stress leads to the accumulation of unfolded proteins in the ER lumen where they form highly toxic aggregates. If these toxic aggregates reach critical levels, ER stress response and apoptotic signaling are initiated (4).

The ER stress response is primarily regulated by three ER transmembrane proteins; protein kinase-like endoplasmic reticulum kinase (PERK), activating transcription factor-6 (ATF-6), and inositol requiring kinase-1 (IRE-1) (5). In normal condition, these proteins remain inactive and bound to ER-resident chaperone glucose-regulated protein-78 (GRP-78/BiP). During ER stress, GRP-78 dissociates from these proteins (5). Dissociated RERK and IRE-1 are then free to form homo-dimers, which lead to their autophosphorylation and activation (5). Activated PERK then phosphorylates and inactivates eukaryotic initiation factor-2 $\alpha$ (eIF-2 $\alpha$ ), leading to an overall suppression in translation $(6,7)$, whereas activated IRE-1 converts X-box transcription factor-1 (XBP-1) pre-mRNA into mature mRNA by unconventional splicing. The protein translated from this spliced XBP-1 mRNA mediates transcriptional activation of ER-associated degradation component genes (8). Dissociation of ATF-6 from GRP-78 permits its translocation to the Golgi apparatus where it is sequentially cleaved (activated) by proteases (9). The activated cytoplasmic fragment of ATF- 6 then binds to the ER stress response element in the nucleus to activate transcription of ER chaperone genes such as GRP-78 and transcription factor genes such as XBP-1, and expression of CCAAT/enhancer-binding protein-homologous protein (CHOP/GADD153) $(9,10)$. Severe or prolonged ER stress stimulates RERK, ATF-6 and IRE-1 
apoptotic signaling and increases CHOP expression. CHOP is the major component of the ER stress pathway, and CHOP knockdown cells are resistant to ER stress-induced apoptosis (11). Caspase-12 has also been implicated in ER stress-mediated cell death, and caspase-12 knockdown mice are resistant to ER stress-induced apoptosis (12).

Accumulating evidence suggests that anticancer agents are toxic to cancer cells because they increase oxidative stress, pushing the cancer cells beyond their limits (13-15). Cytotoxic reactive oxygen species (ROS) appears to be triggered by activation of the mitochondrial-dependent cell death pathway via bcl-2 family proteins, with consequent mitochondrial membrane permeabilization and apoptosis (16).

20-O-( $\beta$-D-glucopyranosyl)-20(S)-protopanaxadiol (Compound $\mathrm{K}$, Fig. 1A) is the main metabolite of protopanaxadioltype ginsenoside formed in the intestine after oral administration (17-20). Ginseng saponin was reported to show beneficial roles on abnormal coronary contraction (21) and possess therapeutic effect on skin wound healing (22). Our previous studies show that Compound $\mathrm{K}$ enhances gamma ray-induced apoptosis via generation of ROS and disruption of the mitochondrial membrane in human lung cancer cells (23), and induces mitochondria- and caspase-dependent apoptosis via the generation of ROS in human colon cancer cells (24). Furthermore, Compound K exhibits anti-proliferative effects against cancer cells, which are mediated via apoptosis (23-29). Despite evidence for the anti-proliferative effects of Compound $\mathrm{K}$, the underlying cytotoxic mechanisms with respect to ER stress-mediated apoptosis have not been reported. Therefore, the aim of the present study was to determine the role of ER stress in mediating Compound K-induced apoptosis in HT-29 human colon cancer cells.

\section{Materials and methods}

Preparation of Compound K. Compound $\mathrm{K}$ was provided by Professor Dong Hyun Kim (Kyung Hee University, Seoul, Republic of Korea). Compound K was prepared by the incubation of protopanaxadiol type ginsenosides with Bacteroides JY-6, a human intestinal bacterium, subcultured in a general anaerobic medium for $24 \mathrm{~h}$ at $37^{\circ} \mathrm{C}$. The incubated medium was extracted with n-butanol. The supernatant was concentrated in vacuo and processed using silica gel column chromatography with chloroform/methanol/ $\mathrm{H}_{2} \mathrm{O}$ (65:35:10). The isolated Compound $\mathrm{K}$ was characterized by mass spectroscopy and ${ }^{1} \mathrm{H}$ and ${ }^{13} \mathrm{C}$ nuclear magnetic resonance (NMR) spectrometry.

Reagents. Propidium iodide (PI) was purchased from Sigma Chemical Company (St. Louis, MO, USA). CHOP, caspase-12, ATF- 6 and B-actin antibodies were purchased from Cell Signaling Technology (Beverly, MA, USA). Phospho PERK, phospho eIF-2 $\alpha$, phospho IRE-1, XBP-1 and GRP-78 antibodies were purchased from Santa Cruz Biotechnology (Santa Cruz, CA, USA). All other chemicals and reagents were of analytical grade.

Cell culture. HT-29 human colon cancer cells were obtained from the American Type Culture Collection (Rockville, MD, USA) and maintained at $37^{\circ} \mathrm{C}$ in an incubator with a humidified atmosphere of $5 \% \mathrm{CO}_{2}$ in air. Cells were cultured in RPMI-1640 containing $10 \%$ heat-inactivated fetal calf serum, streptomycin $(100 \mu \mathrm{g} / \mathrm{ml})$ and penicillin $(100 \mathrm{U} / \mathrm{ml})$.

DNA fragmentation. Cells were seeded at a concentration of $5 \times 10^{4}$ cells $/ \mathrm{ml}$, and $16 \mathrm{~h}$ after plating, were treated with Compound $\mathrm{K}$ at $20 \mu \mathrm{g} / \mathrm{ml}$ and incubated for $48 \mathrm{~h}$. Cellular DNA fragmentation was assessed using the cytoplasmic histoneassociated DNA fragmentation kit from Roche Diagnostics (Mannheim, Germany) according to the manufacturer's instructions.

Detection of sub- $G_{I}$ hypodiploid cells. The amount of apoptotic sub- $\mathrm{G}_{1}$ hypodiploid cells was determined by flow cytometry (30). Cells were seeded at a six-well plate at a concentration of $1 \times 10^{5}$ cells $/ \mathrm{ml}$, and $16 \mathrm{~h}$ after plating, were treated with Compound $\mathrm{K}$ at $20 \mu \mathrm{g} / \mathrm{ml}$ for $48 \mathrm{~h}$. Harvested cells were washed twice with phosphate buffered saline (PBS) and fixed in 70\% ethanol for $30 \mathrm{~min}$ at $4^{\circ} \mathrm{C}$. Cells were incubated for $30 \mathrm{~min}$ in the dark at $37^{\circ} \mathrm{C}$ in $1 \mathrm{ml} \mathrm{PBS}$ containing $100 \mu \mathrm{g}$ PI and $100 \mu \mathrm{g}$ RNase A. Flow cytometric analysis was performed using a FACS Calibur flow cytometer (Becton Dickinson, Mountain View, CA, USA). The proportion of sub- $\mathrm{G}_{1}$ hypo-diploid cells was assessed by the histograms generated using the computer program Cell Quest and Mod-Fit (Becton Dickinson).

Cytosolic $\mathrm{Ca}^{2+}$ measurement. Cytosolic $\mathrm{Ca}^{2+}$ was detected with the fluorescent probe Fluo4 AM. Cells were seeded at a concentration of $1 \times 10^{5} \mathrm{cells} / \mathrm{ml}$, and $16 \mathrm{~h}$ after plating, were treated with Compound $\mathrm{K}$ at $20 \mu \mathrm{g} / \mathrm{ml}$ and incubated for $24 \mathrm{~h}$. Cells were then harvested and loaded with $10 \mu \mathrm{M}$ of Fluo4 AM for $30 \mathrm{~min}$ at $37^{\circ} \mathrm{C}$ and the supernatant was removed by suction and after trypsin treatment, cells were washed with PBS. The fluorescence of Fluo4 AM-loaded cells was measured using a flow cytometer.

Measurement of mitochondrial $\mathrm{Ca}^{2+}$. A Rhod2 AM probe (Molecular Probes, Eugene, OR, USA) was used to determine mitochondrial $\mathrm{Ca}^{2+}$ level (31). Rhod2 AM has a net positive charge, which facilitates its sequestration into mitochondria via membrane potential-driven uptake. The use of Rhod2 AM enhances the selectivity for mitochondrial loading because the dye exhibits $\mathrm{Ca}^{2+}$-dependent fluorescence only after it is oxidized, and this occurs preferentially within mitochondria. Cells were seeded at a concentration of $1 \times 10^{5}$ cells $/ \mathrm{ml}$, and $16 \mathrm{~h}$ after plating, were treated with Compound $\mathrm{K}$ at $20 \mu \mathrm{g} / \mathrm{ml}$ and incubated for $24 \mathrm{~h}$. Cells were harvested, washed, and resuspended in PBS containing Rhod 2 AM $(1 \mu \mathrm{M})$. After 15 min of incubation at $37^{\circ} \mathrm{C}$, cells were washed, suspended in PBS and analyzed by flow cytometry. For image analysis, cells were loaded with Rhod $2 \mathrm{AM}$ and incubated for $30 \mathrm{~min}$ at $37^{\circ} \mathrm{C}$. Cells were then washed, and the stained cells mounted onto microscope slides with mounting medium (Dako, Carpinteria, CA, USA). Microscopic images were examined using a confocal laser scanning microscope and the 5 PASCAL program (Carl Zeiss, Jena, Germany).

Fluorescent microscopy and ER staining. Cells were seeded in Lab-Tek chamber slides (Nalge Nunc International, Naperville, IL, USA) at a density of $1 \times 10^{5}$ cells $/ \mathrm{ml}$, and $16 \mathrm{~h}$ after plating, were treated with Compound $\mathrm{K}$ at $20 \mu \mathrm{g} / \mathrm{ml}$ and incubated for 
A

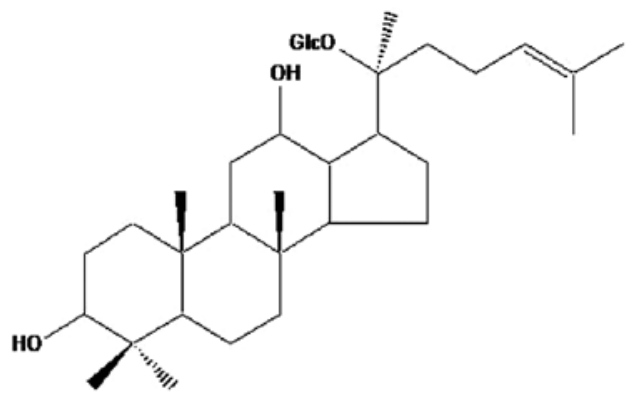

B

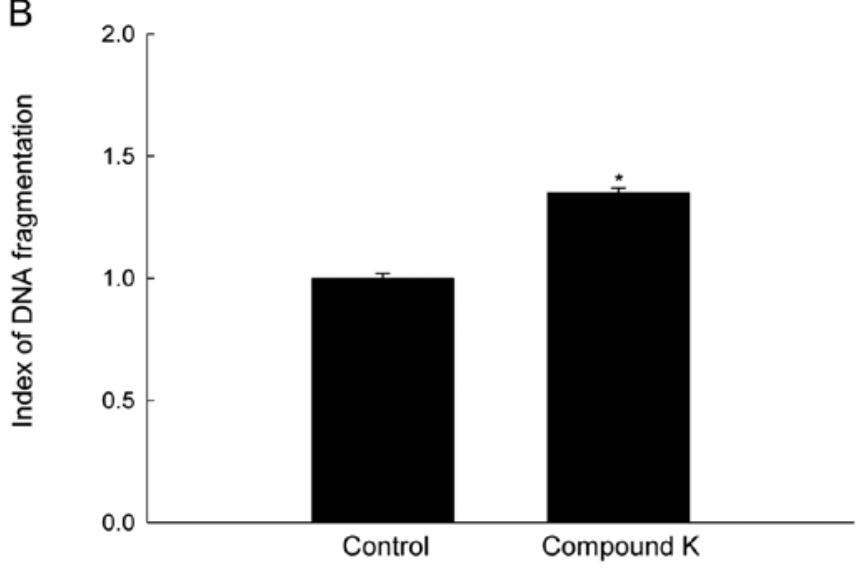

C
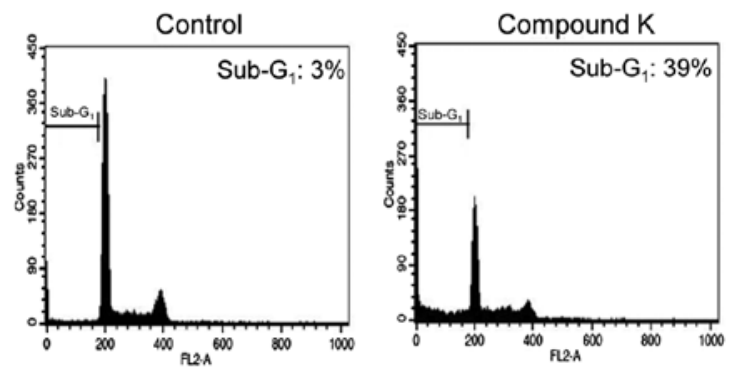

Figure 1. Chemical structure of Compound $\mathrm{K}$ and induction of apoptosis by Compound K. (A) The chemical name for Compound $\mathrm{K}$ is 20-O-D-glucopyranosyl-20(S)-protopanaxadiol. (B) DNA fragmentation was quantified using an ELISA kit and (C) the apoptotic sub- $\mathrm{G}_{1}$ DNA content was detected by flow cytometry after PI staining. Significantly different from control $\left({ }^{*} \mathrm{p}<0.05\right)$.

24 h. For ER staining, the ER-Tracker Blue-White DPX probe (Molecular Probes) was added to the cells and incubated for 30 min under the same growth conditions. The loading solution was removed and cells were then washed with PBS before adding fresh medium without the stain. Microscopic images were collected using the laser scanning microscope 5 Pascal program (Carl Zeiss) as described above.

Western blot analysis. Cells were seeded at a concentration of $1.5 \times 10^{5}$ cells $/ \mathrm{ml}$, and $16 \mathrm{~h}$ after plating, were treated with Compound $\mathrm{K}$ at $20 \mu \mathrm{g} / \mathrm{ml}$, After 3, 6, 12, 24 or $48 \mathrm{~h}$, cells were harvested, washed twice with PBS, lysed on ice for 30 min in $100 \mu \mathrm{l}$ of lysis buffer $[120 \mathrm{mM} \mathrm{NaCl}, 40 \mathrm{mM}$ Tris ( $\mathrm{pH} 8.0), 0.1 \% \mathrm{NP} 40]$ and then centrifuged at $13,000 \mathrm{x} \mathrm{g}$ for $15 \mathrm{~min}$. The supernatants were collected from the lysates and the protein concentrations were determined. Aliquots of the lysates (40 $\mu \mathrm{g}$ of protein) were boiled for $5 \mathrm{~min}$ and electrophoresed in $10 \%$ SDS-PAGE gel. The proteins in the gels were transferred onto nitrocellulose membranes and incubated with the primary antibodies. The membranes were subsequently incubated with the secondary immunoglobulin-G-horseradish peroxidase conjugates (Pierce, Rockford, IL, USA). Protein bands were detected using an enhanced chemiluminescence western blotting detection kit (Amersham, Little Chalfont, Buckinghamshire, UK), and then exposed to X-ray film.

Transient transfection of small RNA interference (siRNA). Cells were seeded in 24-well plate at a density of $1.5 \times 10^{5}$ cells $/ \mathrm{ml}$ and allowed to reach $\sim 50 \%$ confluence on the day of transfection. The siRNA construct used were: mismatched siControl RNA (Santa Cruz Biotechnology) and siCHOP RNA (Bioneer Corporation, Bioneer, South Korea). Cells were transfected with 10-50 nM siRNA using Lipofectamine ${ }^{\mathrm{TM}} 2000$ (Invitrogen, Carlsbad, CA, USA) according to the manufacturer's instructions. After $24 \mathrm{~h}$, cells were treated with Compound $\mathrm{K}$ for $48 \mathrm{~h}$ and examined by western blot analysis, DNA fragmentation assay and PI staining.

Statistical analysis. All the measurements were made in triplicate and all values are represented as the mean \pm standard error of the mean (SEM). Differences in results were analyzed using analysis of variance (ANOVA) and the Tukey test. $\mathrm{p}<0.05$ was considered significant.

\section{Results}

Induction of apoptosis in human colon cancer cells by Compound $K$ treatment. A recent study showed that Compound $\mathrm{K}$ induces mitochondria- and caspase-dependent apoptosis in HT-29 cells via the generation of ROS (24). The results of the present study showed that $20 \mu \mathrm{g} / \mathrm{ml}$ of Compound $\mathrm{K}$, which is a concentration of $50 \%$ growth inhibition, increased DNA fragmentation and sub- $\mathrm{G}_{1}$ phase of cell population, which are hallmarks of apoptosis (Fig. 1B and C).

Compound $\mathrm{K}$ induces cytosolic and mitochondrial $\mathrm{Ca}^{2+}$ overloading and ER stress. Depletion of ER calcium stores induces ER stress, which leads to an increase in cytosolic and mitochondrial $\mathrm{Ca}^{2+}$ levels $(32,33)$. Therefore, the effect of Compound $\mathrm{K}$ on the mobilization of $\mathrm{Ca}^{2+}$ was examined. Compound $\mathrm{K}$ resulted in significant increases in cytosolic (Fig. 2A) and mitochondrial $\mathrm{Ca}^{2+}$ levels (Fig. $2 \mathrm{~B}$ and $\mathrm{C}$ ) at $24 \mathrm{~h}$ after Compound $\mathrm{K}$ treatment. ER stress increases the fluorescence intensity of the ER-Tracker Blue-White DPX dye (34). As shown in Fig. 2D, Compound $\mathrm{K}$ significantly increased the staining intensity of this dye, suggesting the induction of ER stress.

Compound $K$ increases the level of ER stress-related proteins. During ER stress, the activated phospho form of PERK phosphorylates eIF-2 $\alpha$, leading to the attenuation of translational initiation and protein synthesis $(35,36)$. As shown in Fig. 3, Compound $\mathrm{K}$ induced the expression of both phosphorylated PERK and phosphorylated eIF-2 $\alpha$ in a time-dependent manner. Also, the activated phospho form of IRE-1 splices XBP-1, leading to increase in membrane phospholipids and expansion of the surface area and volume of the rough ER (37). As shown in 
B
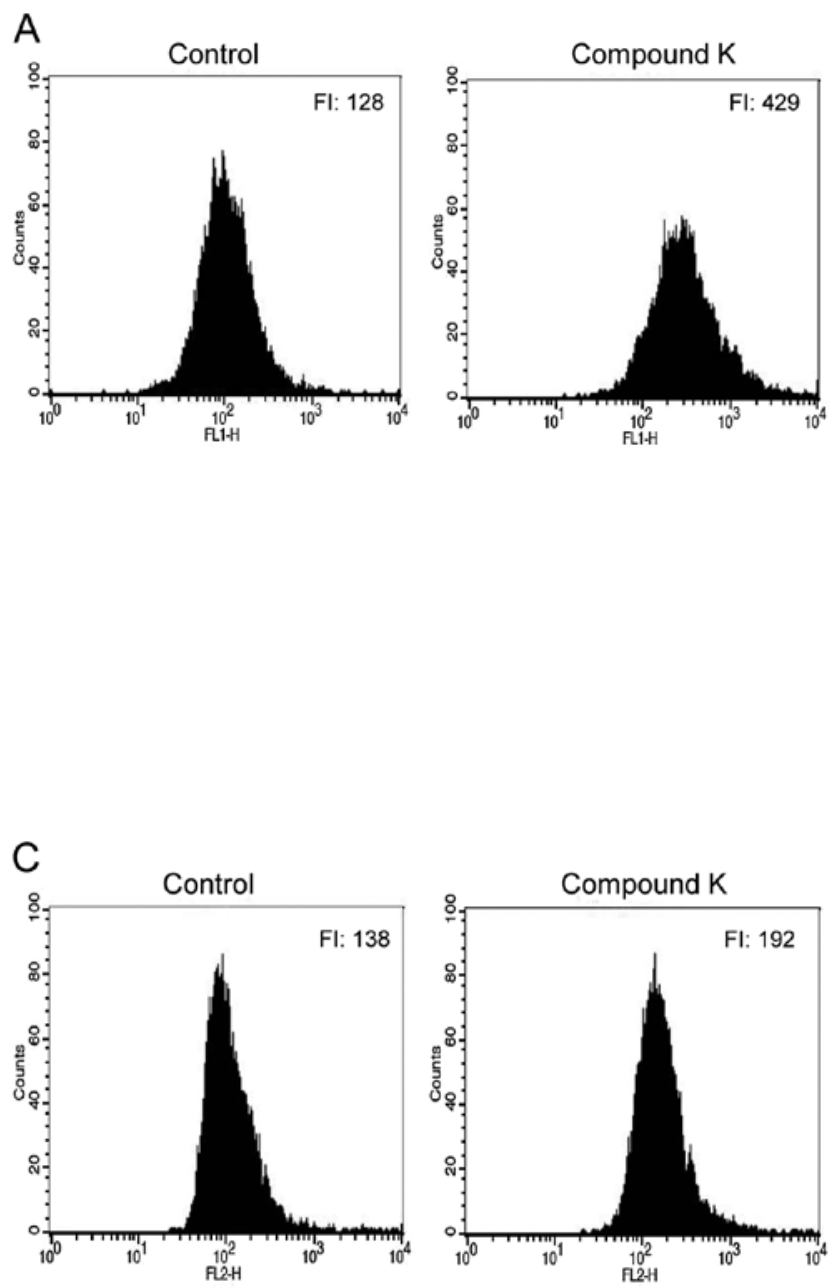

D
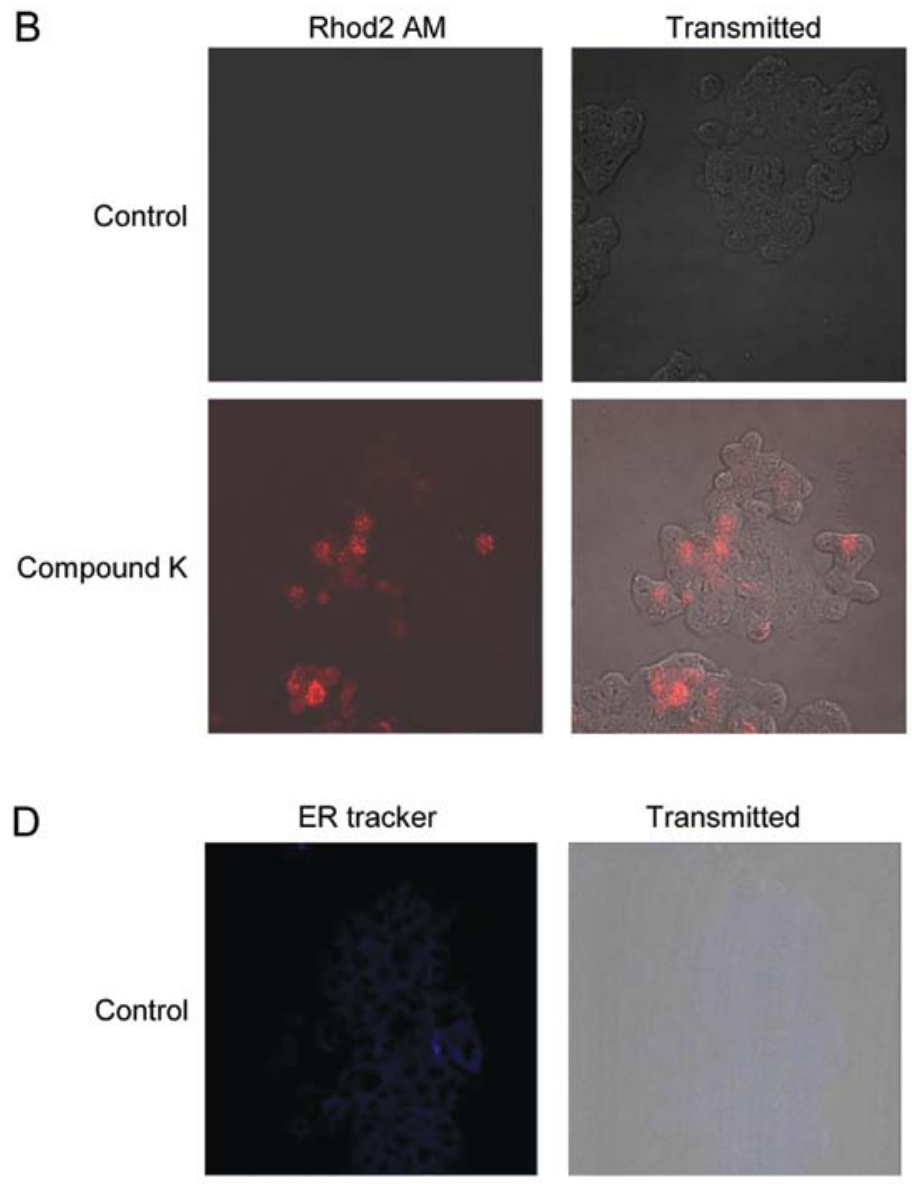

Compound K
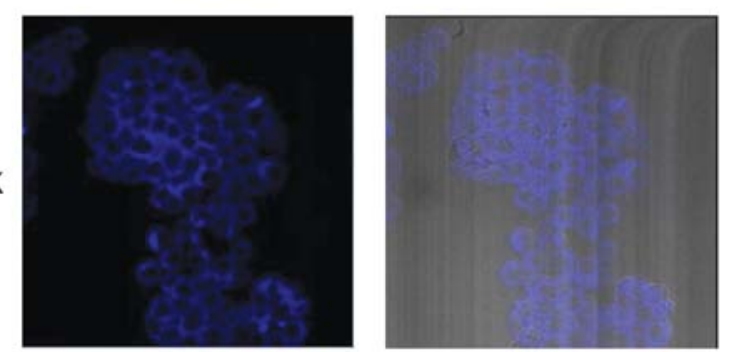

Figure 2. Compound $\mathrm{K}$ enhanced cytosolic and mitochondrial $\mathrm{Ca}^{2+}$ overloading and ER staining. Cells were treated with $20 \mu \mathrm{g} / \mathrm{ml}$ of Compound $\mathrm{K}$ for $24 \mathrm{~h}$, and then harvested and treated with the fluorescent probes Fluo4 AM and Rhod2 AM, respectively. (A) Cytosolic $\mathrm{Ca}^{2+}$ levels were measured by flow cytometry and mitochondrial $\mathrm{Ca}^{2+}$ levels were measured by (B) confocal microscopy and (C) flow cytometry. FI indicates the fluorescence intensity of Fluo4 AM and Rhod2 AM, respectively. The representative confocal microscopic images illustrate the increase in red fluorescence intensity of Rhod 2 AM produced by mitochondrial $\mathrm{Ca}^{2+}$ overloading in Compound K-treated cells compared to the control. (D) Cells were treated with Compound K for $24 \mathrm{~h}$, followed by the ER Tracker Blue-White DPX dye and fluorescence intensity measured by confocal microscopy. The representative confocal microscopic images illustrate the increase in blue fluorescence intensity of the ER Tracker in Compound K-treated cells compared to the control.

Fig. 3, Compound $\mathrm{K}$ induced the expression of phosphorylated IRE-1 and spliced XBP-1 protein in a time-dependent manner. Other hallmarks of the ER stress responses include activation of ATF-6, the subsequent induction of GRP-78 and CHOP, and the activation of caspase-12 $(32,38,39)$. Compound $\mathrm{K}$ also enhanced ATF-6 activation, induced the expression of GRP-78 and CHOP, and activated caspase-12 (Fig. 3).

Suppression of CHOP expression attenuates Compound $\mathrm{K}$ induced apoptosis. CHOP plays a proapoptotic role during ER stress $(38,40)$. Suppression of siRNA-mediated CHOP expression attenuated the apoptotic cell death induced by Compound $\mathrm{K}$, which was confirmed by the DNA fragmentation pattern and the sub- $\mathrm{G}_{1}$ cell population (Fig. $4 \mathrm{~A}$ and B). These results suggest that upregulation of CHOP may, in part, be involved in Compound K-induced apoptosis.

\section{Discussion}

Although Compound $\mathrm{K}$ induces apoptosis in many cancer cell lines (23-29), the underlying mechanisms are not well understood. The central novel finding of this study provides important evidence to support the involvement of ER stress in the induction of apoptosis by Compound K in HT-29 cells.

The ER is the primary site of protein synthesis, folding and trafficking. Under various stressful conditions, the accumulation 


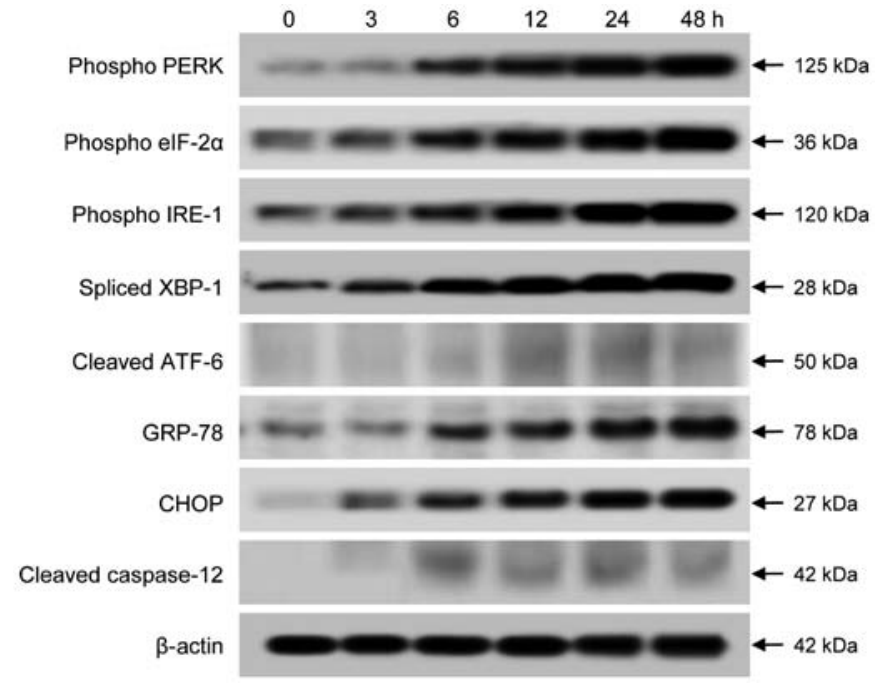

Figure 3. Compound K induced ER stress-related proteins. Cell lysates were subjected to electrophoresis, and phosphorylated PERK, phosphorylated eIF- $2 \alpha$, phosphorylated IRE-1, spliced XBP-1, cleaved ATF-6, GRP-78, CHOP and cleaved caspase-12 were detected using their respective specific antibodies.

of unfolded or misfolded proteins in the ER results in ER stress $(1,2)$. Under conditions of ER stress, the elevation of cytosolic or mitochondrial $\mathrm{Ca}^{2+}$ levels, or the depletion of $\mathrm{ER} \mathrm{Ca}^{2+}$ stores are typical ER stress responses of cells. The present study shows that Compound $\mathrm{K}$ induced the elevation of cytosolic and mitochondrial $\mathrm{Ca}^{2+}$ levels and ER staining. Compound $\mathrm{K}$ also induced apoptosis as assessed by increased DNA fragmentation and sub- $\mathrm{G}_{1}$ phase of cell population. The experimental evidence presented here shows that the induction of ER stress-related proteins may be involved in Compound $\mathrm{K}$-induced apoptosis as: i) Compound $\mathrm{K}$ induces phosphorylation of PERK and eIF-2 $\alpha$; ii) Compound $\mathrm{K}$ induces phosphorylation of IRE-1 and the spliced XBP transcription factor; iii) Compound $\mathrm{K}$ induces cleavage of ATF-6, and subsequent GRP-78 and CHOP expression; and iv) Compound $\mathrm{K}$ induces caspase-12 cleavage. Among ER-associated apoptotic molecules, CHOP and caspase-12 are major proapoptotic factors that are closely associated with ER stress (11). Taken together, these observations demonstrate that Compound $\mathrm{K}$ induces ER-mediated apoptosis. ER stress response pathways are normally activated as a protective mechanism to ensure cell survival (41). However, during severe ER stress, activation of these pathways leads to increased CHOP expression, which is a crucial element that switches ER stress signaling from pro-survival to proapoptosis (42). The CHOP protein is a member of the CCAAT/enhancer-binding proteins and functions as a dominant-negative inhibitor of gene transcription (38). Expression of CHOP is mainly regulated at the transcriptional level through the PERK/eIF-2 $\alpha /$ ATF-6 pathway (38). CHOP knockout mice show reduced apoptosis in response to ER stress (43). Therefore, CHOP is one of the components of the ER stress-mediated apoptosis pathway. In the present study, suppression of CHOP using CHOP siRNA attenuated Compound K-induced apoptosis.

In summary, Compound K induces the apoptosis of HT-29 colon cancer cells which is mediated by ER stress signaling pathway and this is the first report to reveal that the association between the capacity of Compound $\mathrm{K}$ to induce ER stress and apoptosis in colon cancer cells.

\section{Acknowledgements}

This work was supported by the research grant from Jeju National University Hospital. And this study was supported by a grant from the National R\&D Program for Cancer Control, Ministry for Health and Welfare, Republic of Korea (1120340).
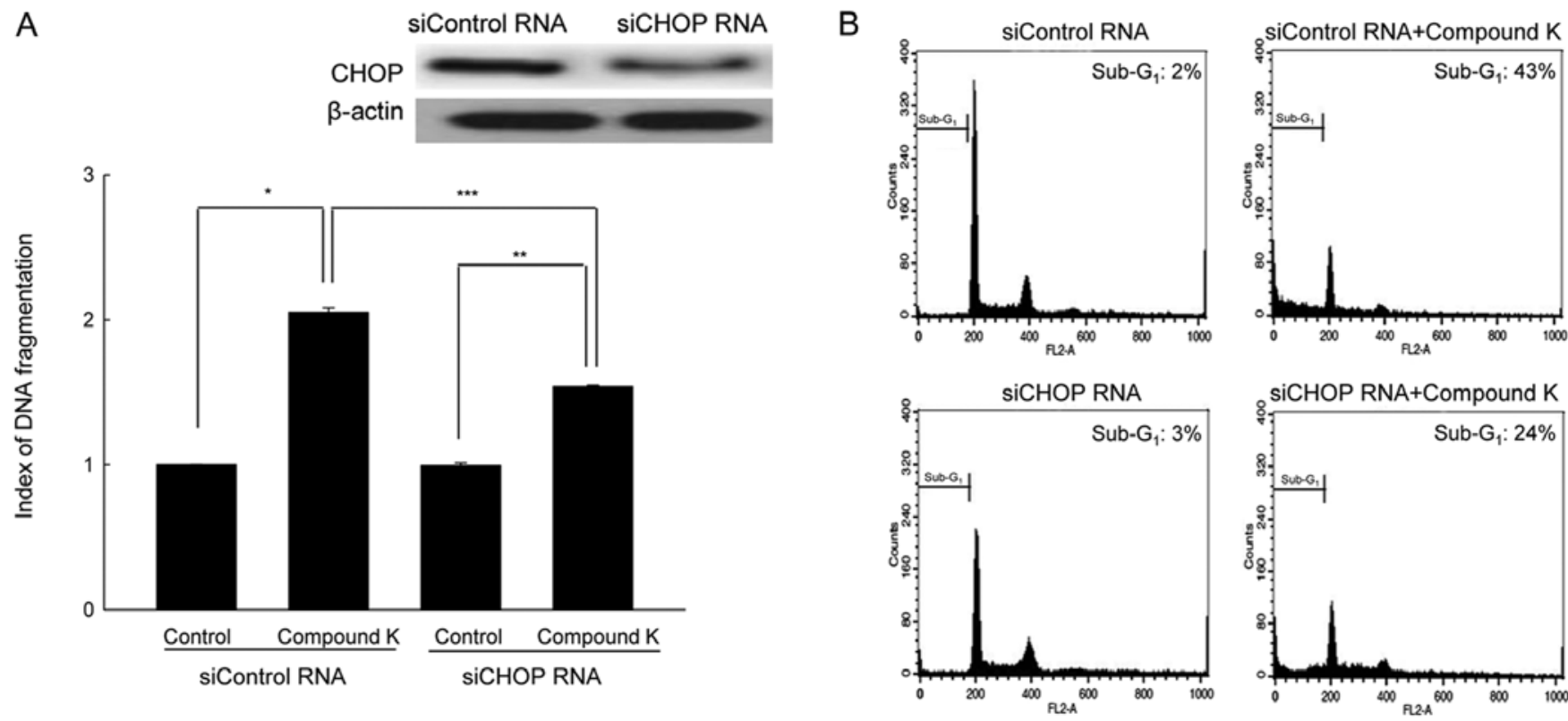

Figure 4. Downregulation of CHOP attenuated Compound K-induced apoptosis. Cells were transfected with siCHOP RNA or siControl RNA after treatment with Compound $\mathrm{K}$ for $48 \mathrm{~h}$, (A) DNA fragmentation was quantified using an ELISA kit and (B) the apoptotic sub-G $\mathrm{G}_{1}$ DNA content was detected by flow cytometry after PI staining. Significantly different from siControl RNA-treated cells ( $\left.{ }^{*} \mathrm{p}<0.05\right)$, significantly different from siCHOP RNA-treated cells $\left({ }^{* *} \mathrm{p}<0.05\right)$, and significantly different from Compound K-treated siControl RNA-treansfected cells $\left({ }^{* * *} \mathrm{p}<0.05\right)$. 


\section{References}

1. Ilieva EV, Kichev A, Naudi A, Ferrer I, Pamplona R and Portero-Otin M: Mitochondrial dysfunction and oxidative and endoplasmic reticulum stress in argyrophilic grain disease. J Neuropathol Exp Neurol 70: 253-263, 2011.

2. Dolai S, Pal S, Yadav RK and Adak S: Endoplasmic reticulum stress-induced apoptosis in Leishmania through $\mathrm{Ca}^{2+}$-dependent and caspase-independent mechanism. J Biol Chem 286: 13638-13646, 2011.

3. Song HS, Kim HM, Jung SK and Lee DH: Characterization of tunicamycin as anti-obesity agent. Biomol Ther 17: 162-167, 2009.

4. Yoshida H: ER stress and diseases. FEBS J 274: 630-658, 2007.

5. Szegezdi E, Logue SE, Gorman AM and Samali A: Mediators of endoplasmic reticulum stress-induced apoptosis. EMBO Rep 7: 880-885, 2006

6. Vattem KM and Wek RC: Reinitiation involving upstream ORFs regulates ATF4 mRNA translation in mammalian cells. Proc Natl Acad Sci USA 101: 11269-11274, 2004.

7. Ma K, Vattem KM and Wek RC: Dimerization and release of molecular chaperone inhibition facilitate activation of eukaryotic initiation factor-2 kinase in response to endoplasmic reticulum stress. J Biol Chem 277: 18728-18735, 2002.

8. Calfon M, Zeng H, Urano F, et al: IRE1 couples endoplasmic reticulum load to secretory capacity by processing the XBP-1 mRNA. Nature 415: 92-96, 2002.

9. Kim R, Emi M, Tanabe K and Murakami S: Role of the unfolded protein response in cell death. Apoptosis 11: 5-13, 2006.

10. Okada T, Yoshida H, Akazawa R, Negishi M and Mori K Distinct roles of activating transcription factor 6 (ATF6) and double-stranded RNA-activated protein kinase-like endoplasmic reticulum kinase (PERK) in transcription during the mammalian unfolded protein response. Biochem J 366: 585-594, 2002.

11. Wali VB, Bachawal SV and Sylvester PW: Endoplasmic reticulum stress mediates gamma-tocotrienol-induced apoptosis in mammary tumor cells. Apoptosis 14: 1366-1377, 2009.

12. Nakagawa T, Zhu H, Morishima N, et al: Caspase-12 mediates endoplasmic-reticulum-specific apoptosis and cytotoxicity by amyloid-beta. Nature 403: 98-103, 2000.

13. Cordero MD, Sanchez-Alcazar JA, Bautista-Ferrufino MR, et al: Acute oxidant damage promoted on cancer cells by amitriptyline in comparison with some common chemotherapeutic drugs Anticancer Drugs 21: 932-944, 2010.

14. Cvorovic J, Tramer F, Granzotto M, Candussio L, Decorti G and Passamonti S: Oxidative stress-based cytotoxicity of delphinidin and cyanidin in colon cancer cells. Arch Biochem Biophys 501: 151-157, 2010.

15. Zhang R, Niu Y and Zhou Y: Increase the cisplatin cytotoxicity and cisplatin-induced DNA damage in HepG2 cells by XRCC1 abrogation related mechanisms. Toxicol Lett 192: 108-114, 2010.

16. Roos WP and Kaina B: DNA damage-induced cell death by apoptosis. Trends Mol Med 12: 440-450, 2006.

17. Akao T, Kida H, Kanaoka M, Hattori M and Kobashi K: Intestinal bacterial hydrolysis is required for the appearance of compound $\mathrm{K}$ in rat plasma after oral administration of ginsenoside $\mathrm{Rb} 1$ from Panax ginseng. J Pharm Pharmacol 50: 1155-1160, 1998.

18. Hasegawa H, Sung JH and Huh JH: Ginseng intestinal bacterial metabolite IH901 as a new anti-metastatic agent. Arch Pharm Res 20: 539-544, 1997.

19. Hasegawa H, Sung JH and Benno Y: Role of human intestinal Prevotella oris in hydrolyzing ginseng saponins. Planta Med 63: 436-440, 1997

20. Akao T, Kanaoka M and Kobashi K: Appearance of compound $\mathrm{K}$, a major metabolite of ginsenoside Rb1 by intestinal bacteria, in rat plasma after oral administration-measurement of compound K by enzyme immunoassay. Biol Pharm Bull 21: 245-249, 1998.

21. Kim HB, Kang CW, Kim BS, et al: Beneficial role of ginseng saponin on hemodynamic functions of porcine blood vessel. J Ginseng Res 34: 314-320, 2010.

22. Kim YS, Cho IH, Jeong MJ, et al: Therapeutic effect of total ginseng saponin on skin wound healing. J Ginseng Res 35: 360-367, 2011
23. Chae S, Kang KA, Chang WY, et al: Effect of compound K, a metabolite of ginseng saponin, combined with gamma-ray radiation in human lung cancer cells in vitro and in vivo. J Agric Food Chem 57: 5777-5782, 2009.

24. Lee IK, Kang KA, Lim CM, et al: Compound K, a metabolite of ginseng saponin, induces mitochondria-dependent and caspasedependent apoptosis via the generation of reactive oxygen species in human colon cancer cells. Int J Mol Sci 11: 4916-4931, 2010.

25. Kang KA, Lim HK, Kim SU, et al: Induction of apoptosis by ginseng saponin metabolite in U937 human monocytic leukemia cells. J Food Biochem 29: 27-40, 2005.

26. Kim AD, Kang KA, Zhang R, et al: Ginseng saponin metabolite induces apoptosis in MCF-7 breast cancer cells through the modulation of AMP-activated protein kinase. Environ Toxicol Pharmacol 30: 134-140, 2010.

27. Choo MK, Sakurai H, Kim DH and Saiki I: A ginseng saponin metabolite suppresses tumor necrosis factor- $\alpha$-promoted metastasis by suppressing nuclear factor- $\kappa \mathrm{B}$ signaling in murine colon cancer cells. Oncol Rep 19: 595-600, 2008.

28. Kim do Y, Yuan HD, Chung IK and Chung SH: Compound K, intestinal metabolite of ginsenoside, attenuates hepatic lipid accumulation via AMPK activation in human hepatoma cells. J Agric Food Chem 57: 1532-1537, 2009.

29. Kim do Y, Park MW, Yuan HD, Lee HJ, Kim SH and Chung SH: Compound $\mathrm{K}$ induces apoptosis via CAMK-IV/AMPK pathways in HT-29 colon cancer cells. J Agric Food Chem 57: 10573-10578, 2009.

30. Nicoletti I, Migliorati G, Pagliacci MC, Grignani F and Riccardi C: A rapid and simple method for measuring thymocyte apoptosis by propidium iodide staining and flow cytometry. J Immunol Methods 139: 271-279, 1991.

31. Hajnóczky G, Robb-Gaspers LD, Seitz MB and Thomas AP: Decoding of cytosolic calcium oscillations in the mitochondria. Cell 82: 415-424, 1995.

32. Cullinan SB and Diehl JA: PERK-dependent activation of Nrf2 contributes to redox homeostasis and cell survival following endoplasmic reticulum stress. J Biol Chem 279: 20108-20117, 2004.

33. Cullinan SB and Diehl JA: Coordination of ER and oxidative stress signaling: the PERK/Nrf2 signaling pathway. Int $J$ Biochem Cell Biol 38: 317-332, 2006.

34. Abdelrahim M, Newman K, Vanderlaag K, Samudio I and Safe S: 3,3'-diindolylmethane (DIM) and its derivatives induce apoptosis in pancreatic cancer cells through endoplasmic reticulum stressdependent upregulation of DR5. Carcinogenesis 27: 717-728, 2006.

35. Jiang HY and Wek RC: Phosphorylation of the alpha-subunit of the eukaryotic initiation factor-2 (eIF2alpha) reduces protein synthesis and enhances apoptosis in response to proteasome inhibition. J Biol Chem 280: 14189-14202, 2005.

36. Moenner M, Pluquet $\mathrm{O}$, Bouchecareilh $\mathrm{M}$ and Chevet E: Integrated endoplasmic reticulum stress responses in cancer. Cancer Res 67: 10631-10634, 2007.

37. Sriburi R, Jackowski S, Mori K and Brewer JW: XBP1: a link between the unfolded protein response, lipid biosynthesis, and biogenesis of the endoplasmic reticulum. J Cell Biol 167: 35-41, 2004.

38. Oyadomari S and Mori M: Roles of CHOP/GADD153 in endoplasmic reticulum stress. Cell Death Differ 11: 381-389, 2004.

39. Rao R, Nalluri S, Kolhe R, et al: Treatment with panobinostat induces glucose-regulated protein 78 acetylation and endoplasmic reticulum stress in breast cancer cells. Mol Cancer Ther 9: 942-952, 2010.

40. Ariyama Y, Tanaka Y, Shimizu H, et al: The role of CHOP messenger RNA expression in the link between oxidative stress and apoptosis. Metabolism 57: 1625-1635, 2008.

41. Boyce M and Yuan J: Cellular response to endoplasmic reticulum stress: a matter of life or death. Cell Death Differ 13: 363-373, 2006.

42. Xu C, Bailly-Maitre B and Reed JC: Endoplasmic reticulum stress: cell life and death decisions. J Clin Invest 115: 2656-2664, 2005.

43. Oyadomari S, Koizumi A, Takeda K, et al: Targeted disruption of the Chop gene delays endoplasmic reticulum stress-mediated diabetes. J Clin Invest 109: 525-532, 2002. 